\title{
Effects of rice straw biochar and nitrogen fertilizer on rice growth and yield
}

\begin{abstract}
Background and Objectives: Nitrogen (N) fertilizer management with other soil amendments is crucial for optimal growth and productivity of grain crops. There has been increasing interest on converting rice straw to biochar and examining its use as a soil amendment. This study was conducted to evaluate the effects of different nitrogen fertilizer managements combined with rice straw derived biochar on rice growth and yield attributes. Materials and Methods: This greenhouse pot study was performed in a randomized complete block design with 4 replications. Treatments comprised of $150 \mathrm{~kg}$ ha- $1 \mathrm{~N}$ fertilizer as a control (T1), $9 \mathrm{t}$ ha-1 rice straw biochar added to 30,60, 90, 120 and $150 \mathrm{~kg} \mathrm{~N}$ ha -1 (T2, T3,T4, T5 and T6, respectively). Growth measurement was carried out at week 2, 6 and 10 after transplanting, while yield attributes were obtained upon harvesting at 110 days. The effects of $\mathrm{N}$ and biochar treatments data were analysed using two-way analysis of variance (ANOVA) in PROC ANOVA in SAS Ver. 9.4 while treatments means differences were compared using least significant difference (LSD), both at $\mathrm{p}<0.05$. Results: Treatment 5 (120 kg N ha-1 with biochar) was able to promote more plant growth and yield attributes than the other treatments, especially in plant height, leaf area, relative chlorophyll content and tiller number. Increased yield over the control treatment was found similar to 90 and $120 \mathrm{~kg} \mathrm{~N}$ ha-1 with biochar, reducing fertilization up to $40 \%$ and resulted in $20 \%$ grain yield improvement compared to the control. Therefore, rice straw biochar addition at $9 \mathrm{t}$ ha-1 with $90-120 \mathrm{~kg} \mathrm{~N}$ ha-1 can be recommended for sustainable rice productivity and improvement of rice yield and farmers' profits. Conclusion: The use of biochar in addition to the chemical fertilizers in rice production systems is an economically feasible and practical nutrient management practice.
\end{abstract}

Keyword: Rice straw biochar; Nitrogen fertilizer; Rice growth; Rice straw 